\title{
Achieving Native-like English Lexical Knowledge: The Non-native Story
}

\author{
Ahmad Azman Mokhtar \\ Academy of Language Studies, Universiti Teknologi Mara Perlis 02600 Arau, Perlis, Malaysia \\ Email: ahmadazman@perlis.uitm.edu.my or azmanrafizah@yahoo.com.my
}

\begin{abstract}
This study which is developmental and cross-sectional in nature examines the receptive and productive English vocabulary knowledge of $L 2$ tertiary students. Vocabulary Levels Test (VLT) which consists of three tests namely Passive Vocabulary Test (PVT), Controlled Active Vocabulary Test (CAVT), and Free Active Vocabulary Test (FAVT) is used to collect the data. When using the test, the researcher is not particularly interested in the students' total score on the tests, but is interested more in whether the students know enough of the high-frequency words. 360 first- and second-year university students are involved in the study. The findings reveal that majority of them have a very limited vocabulary knowledge and vocabulary size to use English as their second language though formal exposure to English language had been given to them for more than 12 years. This paper, besides discussing the students' levels of passive, controlled active and free active vocabulary knowledge and their vocabulary size, highlights the vocabulary levels and vocabulary size they should attain. The probable impact vocabulary knowledge has on the acquisition of other English language skills is another area discussed. Some recommendations for teaching approaches are also put forward.
\end{abstract}

Index Terms - passive vocabulary knowledge, controlled active vocabulary knowledge, free active vocabulary knowledge, vocabulary size

\section{INTRODUCTION}

Words are the tools we use to think, to express ideas and feelings, and to learn about the world. Because words are the very foundation of learning, improving students' vocabulary knowledge is crucial. Studies have shown that limited vocabulary prevents students from comprehending a reading text for example. Poor readers, therefore, often read less because reading is difficult and frustrating for them. This means they do not read enough to improve their vocabulary which could help them comprehend more. This vicious circle means that as students go higher and higher academically, the gap between lexically good and poor students grow wider and wider.

According to Lehr, Osborn and Heibert (2005), vocabulary knowledge comes in two forms namely receptive and productive. Receptive vocabulary includes words that we recognize when we hear or see them. Productive vocabulary, on the other hand, includes words that we use when we speak or write. Receptive vocabulary is typically larger than productive vocabulary.

Thus, what does it mean to "Know" a word? Nagy and Scott (2000) pinpoint several dimensions that describe the complexity of what it means to know a word. First, word knowledge is incremental which means that several exposures to a word in different contexts are needed before "knowing" it. Second, word knowledge is multidimensional which means many words have multiple meanings and serve different functions in different sentences, texts, and even conversations. Third, word knowledge is interrelated in that knowledge of one word connects to knowledge of other words.

Thus, "knowing" a word is a matter of degree rather than an all-or-nothing proposition (Nagy \& Scott, 2000). The degrees of knowing a word are reflected in the precision with which the word is used, how quickly it is understood, and how well the word is understood and used in different modes eg. receptively or productively, and for different purposes eg. formal or informal occasions. In addition, knowing a word also means knowing how that word relates to other knowledge. The more one knows about a specific topic, for instance, the more words one brings to one's understanding of that topic. Because everybody has different interests and backgrounds, one may bring different words to shape that understanding. Finally, knowing a word also means being able to appreciate its connotations and subtleties. When one knows a word at this level, one can use and recognize it in idioms, jokes, slang, and puns (Johnson, Johnson, \& Schlicting, 2004).

Besides discussing the students' levels of receptive and productive vocabulary knowledge, this paper expands its discussion on other issues related to the above findings. The issues discussed are the levels of vocabulary knowledge that Malaysian university students should attain, their chances of reaching native-like vocabulary size, and the influence vocabulary knowledge has on the acquisition of reading, listening, speaking and writing skills. Some pedagogical implications are also put forward.

\section{Methodology}




\section{A. Sample}

Samples are taken from Universiti Teknologi MARA Perlis, Malaysia. The population of the samples at the time of the study is 5413 and according to Wunsch (1986), for a group of 5413 students, at least a sample of 346 is needed to make estimation with a sampling error of \pm 5 percent at 95 percent confidence level. Nevertheless, 360 students are chosen. Out of the 360 students, 126 students are from Semester One, 102 from Semester Two, and Semester Three comprises of 132 students.

\section{B. Vocabulary Levels Test}

The Vocabulary Levels Test which consists of three different vocabulary tests is used to measure the three dimensions of Malaysian students' English vocabulary knowledge. The three different vocabulary tests are:

1) The Passive Vocabulary Test for passive vocabulary size (Nation, 1990);

2) The Controlled Active Vocabulary Test for controlled active vocabulary size (Laufer \& Nation, 1995);

3) The Free Active Vocabulary Test for lexical richness in free written expression (Laufer \& Nation, 1995).

The Passive Vocabulary Test measures receptive vocabulary knowledge and is originally based on words from five word-frequency levels namely the first 2,000 words, 3,000 words, 5,000 words, the University word level (beyond 5,000 words) and 10,000 words. However, in this study only the first four levels are used. Each level is intended to relate to specific vocabulary learning objectives. According to Nation (1990), the 2,000- and 3,000-word levels contain the high-frequency words that all learners need to know in order to function effectively in English. The 5,000-word level represents the upper limit of the general high-frequency vocabulary that is worth spending time on in class. Finally, words at the University level should help students in reading their textbooks and other academic reading material.

The Passive Vocabulary Test involves word-definition matching although, in a reversal of the standard practice, the students are required to match the words to the definitions. Each frequency level of the test comprises six sections and each section includes 6 words and 3 definitions. In other words, there are 36 words and 18 definitions at each level. Although there are only 18 words at each level, Nation (1990) argues that 36 words are tested because the respondents need to check every word against the definitions in order to make the correct matches. Words in each level of the test are representative of all the words at that level. In fact, the test is designed to be sensitive to any vocabulary knowledge held by the students. Therefore, each word in the test is distinctly different within each set of words being tested.

The words for each level are also selected on a random basis but with proper nouns and compound nouns are excluded so that the results of the test would give a reasonable indication of what proportion of the total number of words at each frequency level the students have some knowledge of. In addition, all the words in each group belong to the same word class in order to avoid giving any grammatical clue as to the correct definition. On the other hand, apart from the correct matches, care is taken not to group together words definitions that are related in meaning. The test is intended as a broad measure of word knowledge, without the students to distinguish between semantically related words.

The Passive Vocabulary Test has 72 items (18 in each level). It tests the target words out of context because context might provide clues to their meanings. The researcher is only interested in the number of words the students could understand without any clues, rather than their guessing ability. The answers are scored as correct or incorrect. Each correct answer is given one point. Since the test has 72 items, the maximum score is therefore 72 . "A weak score at any level is defined as knowing fewer than 15 out of 18 items, or less than 83\%" according to Nation's experience using the test (Nation, 1990, pg. 140).

To evaluate the students' productive vocabulary knowledge, two vocabulary tests are used namely the Controlled Active Vocabulary Test and Free Active Vocabulary Test. The Controlled Active Vocabulary Test is modeled on the Passive Vocabulary Test, in which it uses the same frequency bands and the same items. It elicits target items from four frequency levels in short sentences with the items' first few letters provided in order to eliminate other possibilities. The students are to provide the missing word in each sentence. The test has 72 items- 18 in each level. The scoring is in terms of correct ( 1 point) or incorrect/ blank ( 0 point). An item is considered correct when it is semantically correct- the appropriate word is used to express the intended meaning. If used in the wrong grammatical form, it is not marked as incorrect. A word with a spelling error which does not distort the word is not marked as incorrect either. Most of the incorrect answers are non-words or existing words which are incorrect in the provided context. As in the test of passive vocabulary size, the maximum score is 72 . "A weak score at any level is defined as knowing fewer than 15 out of 18 items, or less than 83\%", according to Nation's experience using the test (Nation, 1990, pg. 140).

When testing vocabulary, it is important to distinguish between how well a word is known and how well a word is used. One way to do this is by using the Lexical Frequency Profile (LFP). The LFP measures the amount of vocabulary from different frequency levels used by the students in their composition writing. The measure is normally applied using a computer program called VocabProfile which compares words in a text with word lists that accompany the program. A student's lexical frequency profile is the percentage of word types at the high-frequency level (2000 word family), the University Word List level and not in those levels, totaling 100\%. The LFP does not show how well particular words are known but indicates what use students are making of words at a particular frequency level. This is useful for diagnostic purposes to see if the vocabulary shown to be known on texts like the Vocabulary Levels Test is actually being used in meaning-focused performance. 
In the Free Active Vocabulary Test the students are required to write a composition of about 300-400 words entitled "University education should be made free for all Malaysians. Do you agree?" The compositions then are analyzed using the VocabProfile program. This measure shows the percentage of words in the writing samples that come from different vocabulary frequency levels. For instance, a composition consisting of 200 word families contains 150 belonging to the first 1,000 most frequent words, 20 belonging to the second, 20 from the University Word List and 10 not in any list and if these figures are converted into percentages out of the total of 200 word types, the LFP of the composition is therefore $75 \%-10 \%-10 \%-5 \%$. Laufer (1994) finds that simply taking the percentage of words that are not within the first 2000 words gives a clearer indication of progress in vocabulary use over one or two semesters of university study than the full profile does. The 'beyond 2000' percentage is in fact an alternative way of calculating lexical sophistication. Since the profile always adds up to 100 percent, more words beyond the 2000-word level inevitably means a smaller proportion of the high-frequency words.

The entire calculation is done by the VocabProfile program which matches vocabulary frequency lists with a text that is typed into the program. For the LFP analysis to be performed, the compositions are typed into the program with the following modifications:

1) spelling errors that do not distort the words are corrected in order to make the word recognizable by the program;

2) proper nouns are omitted- they are not considered as belonging to the lexis of a given language;

3) words that are semantically incorrect such as wrong meaning and wrong collocation are omitted as well since they could not be regarded as known by the respondents.

\section{RESULTS}

\section{A. Malaysian Students' Levels of Passive Vocabulary Knowledge}

The Passive Vocabulary Test which has four word-frequency levels namely the first 2000 words, 3000 words, University Word List (UWL), and 5000 words is used to evaluate the students' passive vocabulary knowledge. A weak score at any level is defined as "knowing fewer than 15 out of 18 items, or less than 83\%" according to Nation's (1990, p. 140) experience using the test.

TABLE 1

Passive Vocabulary Test Results

\begin{tabular}{|c|c|c|c|c|c|c|c|c|c|c|c|c|}
\hline \multicolumn{13}{|c|}{ PASSIVE VOCABULARY TEST } \\
\hline \multirow[b]{2}{*}{ Score } & \multicolumn{3}{|c|}{2000 Word Level } & \multicolumn{3}{|c|}{3000 Word Level } & \multicolumn{3}{|c|}{ University Word List } & \multicolumn{3}{|c|}{5000 Word Level } \\
\hline & Sem. 1 & $\begin{array}{c}\text { Sem. } \\
2 \\
\end{array}$ & Sem. 3 & Sem. 1 & Sem. 2 & Sem. 3 & Sem. 1 & Sem. 2 & Sem. 3 & Sem. 1 & Sem. 2 & $\begin{array}{c}\text { Sem. } \\
3 \\
\end{array}$ \\
\hline $\begin{array}{l}\geq 83 \% \\
\text { (Pass) }\end{array}$ & 6 & 9 & 21 & 5 & 10 & 30 & 1 & 3 & 11 & 0 & 1 & 6 \\
\hline $\begin{array}{l}<83 \% \\
\text { (Fail) } \\
\end{array}$ & 120 & 93 & 111 & 121 & 92 & 102 & 125 & 99 & 121 & 126 & 101 & 126 \\
\hline Total & & & & & & & & & & & & \\
\hline Students & 126 & 102 & 132 & 126 & 102 & 132 & 126 & 102 & 132 & 126 & 102 & 132 \\
\hline
\end{tabular}

Based on Table 1, at the 2000 word level, 120 Semester One students, 93 Semester Two and 111 Semester Three are in the weak group. For the 3000 word level, 121 Semester One students, 92 Semester Two and 102 Semester Three students are categorized as weak. Then, 125 Semester One, 99 Semester Two and 121 Semester Three students are in the weak group for the University Word List (UWL). Finally, none of the Semester One students manages to pass the test at the 5000 Word Level; only one Semester Two and six Semester Three students pass. Those results suggest that majority of the students has limited English passive vocabulary knowledge.

Table 2 shows that Semester Three students obtain the highest mean score for the Passive Vocabulary Test (M= 42.57, $\mathrm{SD}=9.92)$. They are followed by Semester $2(\mathrm{M}=35.77, \mathrm{SD}=10.1)$ and Semester $1(\mathrm{M}=32.91, \mathrm{SD}=8.75)$. There is a significant mean difference between the three mean scores, $\mathrm{F}(2,357)=34.51, \mathrm{p}=.000$.

The main scores obtained by Semester One, Semester Two, and Semester Three students in the Passive Vocabulary Test are 33.01, 35.72, and 42.57 respectively. In terms of vocabulary size, the mean scores represent 1528, 1653, and 1968 word families (refer APPENDIX for the calculation). Comparing the passive vocabulary size of Semester One, Semester Two, and Semester Three students, it could be seen that it increases from 1528 to 1653 to 1968 word families in three semesters. In other words, the increase is 440 word families. 
TABLE 2

Comparison of Mean and Standard Deviation OF the Passive Vocabulary Test by Semester $* \mathrm{p}<.05$ PVT= Passive Vocabulary Test UWL= University Word Level

\begin{tabular}{|c|c|c|c|c|c|c|c|c|c|}
\hline \multirow{2}{*}{} & \multicolumn{2}{|c|}{$\begin{array}{c}\text { Semester 1 } \\
(\mathrm{n}=126)\end{array}$} & \multicolumn{2}{c|}{$\begin{array}{c}\text { Semester 2 } \\
(\mathrm{n}=102)\end{array}$} & \multicolumn{2}{c|}{$\begin{array}{c}\text { Semester 3 } \\
(\mathrm{n}=132)\end{array}$} & \multicolumn{3}{c|}{ Difference } \\
\cline { 2 - 11 } & Mean & SD & Mean & SD & Mean & SD & F-value & $p$ & $\mathrm{y}^{2}$ \\
\hline PVT & 33,01 & 8,75 & 35,72 & 10,1 & 42,57 & 9,92 & $34,51^{*}$ & 0.000 & 0,162 \\
\hline 2000 word level & 8,71 & 2,93 & 9,64 & 3,07 & 11,02 & 3,17 & $18,49^{*}$ & 0.000 & 0,094 \\
3000 word level & 8,27 & 2,91 & 9,46 & 3,67 & 11,41 & 3,53 & $28,68^{*}$ & 0.000 & 0.138 \\
UWL & 8,59 & 2,79 & 9,23 & 2,64 & 10,64 & 2,77 & $18,61^{*}$ & 0.000 & 0,094 \\
5000 word level & 7,44 & 2,55 & 7,39 & 2,62 & 9,44 & 2,64 & $25,23 *$ & 0.000 & 0,124 \\
\hline
\end{tabular}

\section{B. Malaysian Students' Levels of Controlled Active Vocabulary Knowledge}

The Controlled Active Vocabulary Test (CAVT) is modeled on the Passive Vocabulary Test. It elicits target items from four frequency word levels in short sentences with the items' first few letters provided in order to eliminate other possibilities. The students provided the missing word in each sentence. A weak score at any level was also defined as "knowing fewer than 15 out of 18 items, or less than 83\%" according to Nation's (1990,pg. 140) experience using the test.

TABLE 3

CONTROLLED ACTIVE VOCABULARY TEST RESUltS

\begin{tabular}{|c|c|c|c|c|c|c|c|c|c|c|c|c|}
\hline \multicolumn{10}{|c|}{ CONTROLLED ACTIVE VOCABULARY TEST } \\
\hline & \multicolumn{2}{|c|}{2000 Word Level } & \multicolumn{2}{|c|}{3000 Word Level } & \multicolumn{2}{c|}{ University Word List } & \multicolumn{3}{c|}{5000 Word Level } \\
\cline { 2 - 14 } \\
\cline { 2 - 14 } \\
\hline $\begin{array}{c}\text { Score } \\
\text { (Pass) }\end{array}$ & 29 & 40 & 62 & 2 & 7 & 17 & 6 & 15 & 17 & 8 & 15 & 17 \\
\hline $\begin{array}{c}\text { Sem. 1 } \\
\text { (Fail) }\end{array}$ & 97 & 62 & 70 & 124 & 95 & 115 & 120 & 87 & 115 & 118 & 87 & 115 \\
\hline $\begin{array}{c}\text { Total } \\
\text { Students }\end{array}$ & 126 & 102 & 132 & 126 & 102 & 132 & 126 & 102 & 132 & 126 & 102 & 132 \\
\hline
\end{tabular}

Based on Table 3, at the 2000 word level, 97 Semester One students are categorized as weak as compared to 62 for Semester Two and 70 Semester Three. As for the 3000 word level, only two Semester One students are not in the weak category. However, Semester Two and Three students have seven and 17 students respectively. Moving to the University Word List (UWL), 120 Semester One, 87 Semester Two, and 115 Semester Three students failed to get the minimum score of 15 correct answers out of 18 which make them eligible to be put in the good group. Finally, results in the 5000 word level indicate that more students fail the test- 118 Semester One students fail followed by 87 Semester Two and 115 Semester Three. Those results suggest that majority of the students are still weak in terms of their controlled active English vocabulary knowledge.

TABLE 4

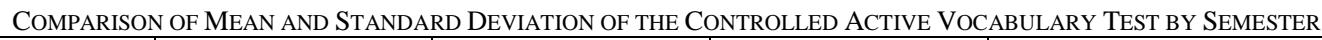

\begin{tabular}{|c|c|c|c|c|c|c|c|c|c|}
\hline & \multicolumn{2}{|c|}{$\begin{array}{l}\text { Semester } 1 \\
(n=126)\end{array}$} & \multicolumn{2}{|c|}{$\begin{array}{l}\text { Semester } 2 \\
(n=102)\end{array}$} & \multicolumn{2}{|c|}{$\begin{array}{l}\text { Semester } 3 \\
(n=132)\end{array}$} & \multicolumn{3}{|c|}{ Difference } \\
\hline & Mean & SD & Mean & SD & Mean & SD & F-value & $p$ & $\mathrm{y}^{2}$ \\
\hline CAVT & 36,53 & 11.26 & 45,71 & 10.42 & 46,53 & 11.61 & $30.15^{*}$ & 0.000 & 0.145 \\
\hline 2000 word level & 11.95 & 3.2 & 13.82 & 2.57 & 13.65 & 2.99 & $14.84 *$ & 0.000 & 0.077 \\
\hline 3000 word level & 8.04 & 2.87 & 10.26 & 2.83 & 10.81 & 3.23 & 30.24 & 0.000 & 0.145 \\
\hline UWL & 8.04 & 3.37 & 10.37 & 3.35 & 11.12 & 3.39 & 28.66 & 0.000 & 0.138 \\
\hline 5000 word level & 8.5 & 3.39 & 11.26 & 3.31 & 10.95 & 3.33 & 24.63 & 0.000 & 0.121 \\
\hline
\end{tabular}


Table 4 shows that Semester Three students score the highest mean for the CAVT $(M=46.54, S D=2.99)$. Semester Two and Semester One students score $\mathrm{M}=45.69, \mathrm{SD}=10.42$ and $\mathrm{M}=36.62, \mathrm{SD}=11.26$ respectively. The three mean scores are significantly different, $\mathrm{F}(2,357)=30.15, \mathrm{p}=.000$.

The mean scores obtained by Semester One, Semester Two, and Semester Three students in the CAVT are 36.53, 45.71, and 46.53 respectively. In terms of vocabulary size, the mean scores represent 1691, 2116, and 2154 word families (refer APPENDIX for the calculation). Comparing the controlled active vocabulary size of Semester One, Semester Two, and Semester Three students, it could be seen that the vocabulary size increases from 1695 to 2116 to 2154 word families. In other words, within two semesters the increase is 459 word families.

\section{Malaysian Students' Levels of Free Active Vocabulary Knowledge}

Lexical Frequency Profile (LFP) which measures the amount of vocabulary from different frequency levels used by the students in their composition writing is utilized to diagnose how well a word is used. A student's lexical frequency profile is the percentage of word types at the high-frequency (2000 word family) level, the University Word List (Xue and Nation, 1984) level, and not in those levels or off-list words- less frequent words, totaling $100 \%$. This is useful for diagnostic purposes to see if the vocabulary shown to be known on texts like the Vocabulary Levels Test is actually being used in meaning-focused performance. Laufer $(1994,1995)$ finds that simply taking the percentage of words that are not within the first 2000 words gives a clearer indication of progress in vocabulary use over one or two semesters of university study than the full profile does. The 'beyond 2000' percentage is in fact an alternative way of calculating lexical sophistication. Since the profile always adds up to 100 percent, more words beyond the 2000-word level inevitably meant a smaller proportion of the high-frequency words.

After analyzing 360 compositions- 126 written by Semester One, 102 by Semester Two, and 132 by Semester Three students- some interesting finding are discovered. First of all, 48 compositions written by Semester One students contained more than $90 \%$ of the $1^{\text {st }} 1000$ words compared to 31 and 34 compositions written by Semester Two and Semester Three students respectively. As for the $2^{\text {nd }} 1000$ words, 37 of Semester One students' compositions consist between $6 \%$ to $13 \%$ of the $2^{\text {nd }} 1000$ words compare to 32 compositions done by Semester Two and 51 by Semester Three students. Next, $4 \%$ to $8 \%$ of the words in 40 of the compositions written by Semester One students are controlled by the University Word List (UWL) compare to 38 for Semester Two and 65 for Semester Three students. Moving to the last level- the off-list words, 17 Semester One students' compositions are occupied by $4 \%$ to $7 \%$ of the off-list words compare to 15 compositions for Semester Two and 16 for Semester Three. Such results suggest that majority of the compositions written by the students mostly consist of high-frequency words; the use of the low-frequency words in their writing is still very limited.

Analyzing the four word levels of the Free Active Vocabulary Test, only the $1^{\text {st }} 1000$ word level and the university word level show significant mean differences between the three groups of students. Semester One students score the highest mean $(M=89.07 \%, S D=2.71)$ for the $1^{\text {st }} 1000$ word level followed by Semester $3(M=88.26 \%, S D=2.34)$ and Semester $2(\mathrm{M}=88.17 \%, \mathrm{SD}=2.85)$. The ANOVA test result confirms the significant mean difference, $\mathrm{F}(2,357)=4.34$, $\mathrm{p}=.014$.

TABLE 5

COMPARISON OF LEXICAL PROFILES FROM THE FREE ACTIVE VOCABULARY TEST By SEMESTER $* \mathrm{p}<.05 \quad$ UWL $=$ University Word Level

\begin{tabular}{|c|c|c|c|c|c|c|c|c|c|}
\hline & \multicolumn{2}{|c|}{$\begin{array}{l}\text { Semester } 1 \\
(n=126)\end{array}$} & \multicolumn{2}{|c|}{$\begin{array}{l}\text { Semester } 2 \\
(n=102)\end{array}$} & \multicolumn{2}{|c|}{$\begin{array}{l}\text { Semester } 3 \\
(n=132) \\
\end{array}$} & \multicolumn{3}{|c|}{ Difference } \\
\hline & Mean & $\mathrm{SD}$ & Mean & SD & Mean & SD & F-value & $p$ & $y^{2}$ \\
\hline 1st 1000 words & $89,07 \%$ & 2,71 & $88,17 \%$ & 2,85 & $88,26 \%$ & 2,34 & $4,34^{*}$ & 0,014 & 0,024 \\
\hline 2nd 1000 words & $5,26 \%$ & 1,75 & $5,50 \%$ & 1,79 & $5,59 \%$ & 1,59 & 1,24 & 0,29 & 0,007 \\
\hline UWL & $3,49 \%$ & 1,48 & $3,95 \%$ & 1,56 & $3,99 \%$ & 1,46 & $4,31^{*}$ & 0,014 & 0,024 \\
\hline Off-list words & $2,09 \%$ & 1,12 & $2,37 \%$ & 1,25 & $2,15 \%$ & 1,12 & 1,77 & 0,17 & 0,01 \\
\hline
\end{tabular}

Table 5 shows that similar result is also obtained for the University Word Level (UWL) where Semester Three scores the highest mean $(\mathrm{M}=3.99 \%, \mathrm{SD}=1.46)$ followed by Semester Two $(\mathrm{M}=3.95 \%, \mathrm{SD}=1.56)$ and $\mathrm{Semester}$ One $(\mathrm{M}=$ $3.49 \%, \mathrm{SD}=1.48)$. ANOVA analysis proves the existence of a significant mean difference, $\mathrm{F}(2,357)=4.31, \mathrm{p}=.014$.

If the students' lexical profiles obtained from the Free Active Vocabulary Test are condensed as shown in Table 6, a significant progress is detected in the free active vocabulary of the students. Their progress is evaluated especially by assessing the beyond 2000 word level. The beyond 2000 word level shows an increase from 5.58\% (Semester 1) to $6.15 \%$ (Semester 3). Even though the increase is minimal $(0.57 \%)$, it is still significant, $F(2,357)=4.56, p=.011$. 
TABLE 6

Comparison of Condensed LeXical Profiles From the Free Active Vocabulary TeSt by SeMESTER $* \mathrm{p}<.05$

\begin{tabular}{|c|c|c|c|c|c|c|c|c|c|}
\hline & \multicolumn{2}{|c|}{$\begin{array}{l}\text { Semester } 1 \\
(n=126)\end{array}$} & \multicolumn{2}{|c|}{$\begin{array}{l}\text { Semester } 2 \\
(n=102)\end{array}$} & \multicolumn{2}{|c|}{$\begin{array}{l}\text { Semester } 3 \\
(n=132)\end{array}$} & \multicolumn{3}{|c|}{ Difference } \\
\hline & Mean & SD & Mean & SD & Mean & $\mathrm{SD}$ & F-value & $p$ & $\mathrm{n}^{2}$ \\
\hline $\begin{array}{l}\text { Basic } 2000 \text { words } \\
\text { Beyond } 2000\end{array}$ & & 2,02 & $93,68 \%$ & 2,08 & $93,85 \%$ & 1,92 & $3,46^{*}$ & 0,032 & 0,019 \\
\hline words & $5,58 \%$ & 1,94 & $6,32 \%$ & 2,08 & $6,15 \%$ & 1,92 & $4,56^{*}$ & 0,011 & 0,025 \\
\hline
\end{tabular}

\section{DISCUSSION}

Since the findings clearly show that majority of Malaysian university students fail to achieve the passing level of the Passive and Controlled Active Vocabulary Test and their writing consists of mostly high-frequency words, a conclusion could be made that they have limited receptive and productive vocabulary knowledge. The situation is quite alarming because the students before entering university have at least formally been exposed to English language in schools for at least 13 years. There are two questions needed to be answered to evaluate the seriousness of the problem. The questions are (1) What are the levels of vocabulary knowledge that Malaysian university students should attain? (2) Can Malaysian university students acquire a vocabulary size comparable to that of native speakers?

Answers for the four followings questions would clarify the levels of vocabulary knowledge that Malaysian university students should attain. The first question is "What vocabulary is needed for reading?" Many studies have concentrated on examining the number of words necessary for the comprehension of written text because vocabulary knowledge is instrumental to reading comprehension; the higher the vocabulary size of the student, the better will be the reading comprehension skills (Qian, 2002; Qian \& Schedl, 2004). Laufer (1997) believes that a threshold vocabulary of 3,000 word families i.e. 5,000 words, is necessary for general text comprehension. Students with vocabulary below that size will have great problems in understanding written texts since reading comprehension will be hampered by lack of word knowledge. Even highly skilled L1 readers cannot achieve the threshold of $70 \%$ reading comprehension if they do not have a solid lexical foundation and master a minimum of 5,000 words. However, Nation (2006) argues that about 4,000 word families plus proper nouns (roughly 10,000 independent word meanings) are needed for reading instructionally (that is, with instructional support) with approximately $95 \%$ of words known in a given text. About 9,000 word families, comprising 98\% of words known in a text, are needed for fluent reading in English. Even without examining closely the concept of word families versus word meanings, this estimate is more realistic than earlier claims of 3,000 to 4,000 word families (Nation \& Waring, 1997; Nation, 2001).

Second, "What vocabulary is needed for listening?" Non-native would need at least $95 \%$ coverage of the running words in the input in order to gain reasonable comprehension and to have reasonable success at guessing from context. A higher coverage of around $98 \%$ (one unknown word in every 50 words or 2 to 3 words per minute) would be better (Nation, 2001). Studies of spoken language especially colloquial spoken language used in informal situations indicate that a vocabulary of around 2,000 word families can provide over 95\% coverage (Schonell, Meddleton, \& Shaw, 1956). More formal academic spoken language would probably require knowledge of the Academic Word List.

Next, "What vocabulary is needed for speaking?" To speak fluently sounding like native speakers, Pawley and Syder (1983) suggest that one should memorize large numbers of collocations. A collocation is "a word or phrase that naturally and frequently occurs before, after, or very near the target vocabulary item" (Folse, 2004). They argue that the reason we can speak our first language fluently and choose word sequences that make us sound like native speakers is because we have stored large numbers of memorized sequences in our brain. Instead of constructing these each time we need to say something, we frequently draw on these ready-made sequences. Frequent collocations deserve attention in the classroom if their frequency is equal to or higher than other high-frequency words that is the frequency of the collocations would be sufficient to place it in the most frequent 2,000 words. In addition, frequent collocation of frequent word also deserves attention. In this case, the collocation itself may not be frequent enough to get into the most frequent 2,000 words but because it is a frequent unpredictable use of a high-frequency word, it deserves classroom time (Nation, 2001). Thus, to process such collocations, a considerable degree of vocabulary knowledge is required. If the vocabulary knowledge is too minimal, the collocations then could not be memorized. If such collocations could not be memorized it means speaking ability is hampered.

Finally, "What vocabulary is needed for writing?" Vocabulary size has been found to play an important role in writing. Several studies show how vocabulary knowledge can influence writing ability. Linnarud (1986) analyzes compositions written in Swedish by native and non-native speakers of Swedish. She correlates the compositions in terms of total number of words for each composition, a number of words per sentence, lexical individuality, and lexical sophistication. She concludes that vocabulary size is the single largest factor in writing quality. Laufer and Nation (1995) use VocabProfile to produce a Lexical Frequency Profile (LFP) of 65 student compositions. The aim of the study is to determine to what extend such a profile would correlate with the students' scores on the Passive Vocabulary Levels Test (PVLT). The study reveals that the higher a learner's vocabulary size, the fewer words used at the 1,000 word level 
and the more used from the University Word List and low-frequency levels in their written work. In sum, lexical richness is often taken to be a reliable measure to assess the quality of a written text because lexical knowledge is presumably the strongest predictor of writing quality (Bacha, 2001; Weigle, 2002). The richer and more varied the vocabulary used in composition, the higher the quality of the writing.

In short, all the answers to the above four questions zoom in to the conclusion that vocabulary acquisition beyond the 3000 word level is basically needed to provide a basis to be competent in English and there is no compromise on that. In other words, 3000 word level is the minimum level of vocabulary knowledge Malaysian students should attain if to function effectively in English.

As for the second question, "Can Malaysian university students acquire a vocabulary size comparable to that of native speakers?" comparing vocabulary size of native and non-native speakers would be a good move. A study by Zechmeister et al. (1995) indicates that the receptive vocabulary size of a college-educated native English speaker is about 17,000 word families. A word family consists of a headword, its inflected forms, and its closely related derived forms (Nation, 2001). Nation and Waring (1997) estimate that the receptive vocabulary size of a university-educated native English speaker is around 20,000 base words while Goulden, Nation, and Read's (1990) study indicates that the receptive vocabulary size range of university-educated native English speakers is between 13,200 to 20,700 base words with an average of 17,200 base words.

Based on the above studies, approximately 17,000 word families should then be the vocabulary size of universityeducated non-native English speakers. The target of 17,000 word families for university-educated non-native English speakers is achievable according to several studies. Since Cervatiuc's (2007) study, for instance, indicates that the average receptive vocabulary size of highly proficient university-educated non-native English speakers range between 13,500 and 20,000 base words, the finding is comparable to university-educated native English speakers' vocabulary size which is around 17,000 word families.

Goulden, Nation, and Read (1990) are also optimistic with the 17,000 word- family target. The quotation below indicates their stance:

Clearly, estimates of vocabulary size of adult native speakers which credit them with vocabularies of 216,000 words (Diller, 1978) or 80,000 words (Miller \& Gilden, 1987) are greatly inflated. It is more likely that the average educated native speaker has a vocabulary of around 17,000 base words and has acquired them at the average rate of about two or three words per day. If native speakers do in fact acquire vocabulary at this relatively slow rate, it would seem that for second language learners, direct teaching and learning of vocabulary is a feasible proposition.(Goulden, Nation, \& Read, 1990, p. 356)

A longitudinal study by Milton and Meara (1995) also views the 17,000 word-family target for university-educated non-native English speakers positively. The study involves 53 European exchange students who are majoring in management science and some in English language and literature teaching. Finding indicates that adult learners of English as a second language could learn 2650 base words per year. A vocabulary acquisition rate of 2650 base words per year would allow adult learners of English as a second language to achieve a native-like vocabulary size of 17,200 base words in approximately 6.5 years.

Though several studies produce positive findings towards the 17,000 word-family target for adult non-native speakers, several factors which might lead to such a scenario should be considered. Cervatiuc's (2007) study was conducted in Canada, an English speaking country, and the 20 participants were immigrant who had resided in Canada for an average of 11.55 years. Goulden, Nation, and Read's (1990) study involved only native speakers and was also conducted in an English speaking country. In Milton and Meara's (1995) study, the rate of 2650 base words per year may not be applicable to average ESL learners since the participants in the study were top and exceptional students.

Nevertheless, the 360 Malaysian students participated in this study may not be able to accomplish the 17,000 wordfamily target due to several reasons. First of all, the 360 participants are residing in Malaysia, a non-English speaking country, so there is a very limited English environment for them. English is normally learned just as a subject in their university. Secondly, the 360 participants are not top or exceptional ESL students. Their command of English is average or below average so their rate of vocabulary learning is expected to be slower. Finally, the present vocabulary size reveals the whole story. Presently, their receptive vocabulary grows at 440 word families per year so they might take approximately 39 years to achieve the 17,200 word-family target. On the other hand, they might also take approximately 37 years for controlled active vocabulary knowledge based on present growth of 459 word families per year.

\section{CONCLUSION AND PEDAGOGICAL IMPLICATIONS}

The purpose of the present study is to profile the receptive and productive vocabulary size of Malaysian university students. The receptive and productive versions of the Vocabulary Levels Test (VLT) have been shown to be reliable and valid measures of vocabulary size for the students. Findings show that they have very limited vocabulary knowledge though have been formally learned the language in schools for not less than 11 years before entering university. Thus, having limited vocabulary knowledge may put the students at the disadvantage as far as learning English is concerned. Several approaches could be taken to overcome the problem. 
First, doing a lot of reading may help. Reading is the most elementary of vocabulary programs. For intermediate and advanced learners with vocabulary above 3,000 or so words, reading exposes them to all remaining words. Even beginning students with limited vocabulary can benefit from reading by using graded-readers- books written with controlled vocabulary and limited range of grammatical structures (Schmitt, 2007). Though vocabulary can also be acquired through spoken discourse, it comprises more frequent words and less low-frequency words (Schonell, Middleton \& Shaw, 1956). Written discourse, on the other hand, tends to use a wide variety of vocabulary, making it a better venue for acquiring a broader range of words.

However, some argue that vocabulary acquired from reading is rather small, and it is only through numerous repeated exposures that a significant number of words are acquired. This means that the odd reading session may not have much of an effect on vocabulary learning. Certain steps nevertheless such as making certain words salient by glossing them clearly in book margin may enhance the vocabulary learning process (Hulstijn, 1992). But what is really needed is extensive reading, as in the book-flood studies where reading is both consistent and takes place over a period of time. In the book-flood session normally advanced students can take advantage of a wide variety of authentic texts. As for beginning students, graded-readers are probably the best. These readers are typically graded into a number of levels. Below are the vocabulary guidelines for the Oxford Bookworms series.

$\begin{array}{ccc}\text { Level } & \text { New words } & \text { Cumulative words } \\ 1 & 400 & 400 \\ 2 & 300 & 700 \\ 3 & 300 & 1,000 \\ 4 & 400 & 1,400 \\ 5 & 400 & 1,800 \\ 6 & 700 & 2,500\end{array}$

These guidelines ensure that vocabulary is systematically recycled and added to as the reader works through the series. Nation (1999) believes that graded readers are helpful to enhance students' vocabulary knowledge as they provide the following benefits: They are an important means of vocabulary expansion, they provide opportunities to practice guessing from context and dictionary skills in a supportive environment where most words are already known, and partially known words are repeatedly met so that they can be consolidated.

For intermediate students, narrow reading may be appropriate. Narrow reading means reading numerous authentic texts but all on the same topic. Reading on one subject means that much of the topic-specific vocabulary will be repeated throughout the course of reading which makes the reading easier and gives the reader a better chance of learning this recurring vocabulary. One example of such approach is reading daily newspapers on an ongoing story. A study done by Hwang and Nation (1989) show that the vocabulary load in a series of running stories is substantially lower than in an equivalent amount of unrelated stories. This is good news because newspapers are often a convenient source of authentic L2 material especially if English is the target language. In addition, running stories seem to be easy to find in newspapers. They report that $19 \%$ of stories in international, domestic, and sports sections of the newspapers they look at are on a recurring topic. In short, narrow reading can accelerate access into authentic materials.

Next, vocabulary research thus far has focused more on reading but vocabulary is obviously necessary for the other three skills as well. There are several ways of improving vocabulary knowledge through listening activities for weak teenage learners. One of them is learners can listen while they also see a written version of what they are listening to. Several graded readers are now accompanied by audiotapes and these can provide useful work for the language laboratory (Nation, 2001).

There is also a growing body of evidence (Elley, 1989; Brett, Rothlein \& Hurley, 1996) showing that students can pick up new vocabulary as they are being read to. The teacher reads a story to them and writes important words on the board as they occur. While reading the story aloud the teacher should repeat sentences and go at a speed that they can easily keep up with. This should be done two or three times a week for a few minutes each time in the same way as a serial occurs on television. Students can also listen to stories that they have already read. Nevertheless, there are several conditions that should first be met. The main conditions are: interest in the content of the story, comprehension of the story, and understanding of the unknown words and retrieval of the meaning of those has not yet strongly established.

In the teaching of writing, many English teachers give more emphasis on the grammatical accuracy of a composition. However, it seems that vocabulary may be the area requiring more attention. Research for instance done by Ellis (1994) shows that lexical errors tend to impede comprehension more than grammatical errors, and native-speaking judges tend to rate lexical errors as more serious than grammatical errors. Furthermore, Dušková's study (1969) also shows that $23 \%$ of the errors in compositions written by Czech learners of English are lexical in nature, the second highest errors committed after articles.

A typical problem is that non-native speakers often use basic vocabulary when writing whereas good native-speaking writer would use more precise lower-frequency words. Improving learners' vocabulary size seems to be the best solution as well as recycling and elaborating receptive vocabulary until it becomes productive. This is achievable by encouraging the use of "productive" learner dictionaries such as the Longman Language Activator (1993) or the Oxford 
Learner's Wordfinder Dictionary (Trappes-Lomax, 1997). These dictionaries allow students to look up basic words that they are likely to know in order to be directed to more precise lexical choices.

English teachers should also be careful not to take dictionary skills for granted. Scholfield (1997) shows that there are a number of things a learner must be able to do to find the correct entry and word meanings from a dictionary: (1) the word's spelling must be guessed even if it has only be heard; (2) alphabetical order must be known to locate the word; (3) the learner must decide the proper word form under which to look up the word or phrase; and (4) for polysemous words, multiple meaning senses must be examined before deciding upon the appropriate one. This complexity suggests that learners should be given some practice in dictionary use at the beginning of a course, or at the very least, made to read and understand the front matter in their dictionaries. Unless this is made a requirement, many learners would neglect this informative source of dictionary knowledge.

Many speaking tasks such as mini-lectures, role-play, and problem solving discussion are not usually thought of as having vocabulary learning goals. Nevertheless, such activities are in fact a very useful means of vocabulary learning. Teachers could adapt various speaking activities to achieve vocabulary learning goals.

Retelling activity is one of them. Retelling activities can take many forms. What is common is that the learners read a text, usually about 100 to 200 words long, and retell it. From a vocabulary point of view, the text provides new vocabulary and a context to help understand the new words. The retelling gives learners the chance to productively retrieve the vocabulary and make generative use of it. Research by Joe (1994) indicates that the absence of the text during the retelling encourages generative use but having it present during the retelling ensures that more of the target vocabulary is used.

Other forms of retelling include 4/3/2 (Maurice, 1983; Arevant \& Nation, 1991) and Read and retell (Simcock, 1993). $4 / 3 / 2$ involves giving the same talk to three different listeners one after the other. Four minutes for the first delivery to the first listener, a three-minute delivery of the same talk to the second listener, and two minutes for the third. The repetition would not be expected to increase the range of generative use but would provide an opportunity for more fluent retrieval.

The Read and tell activity involves re-telling a written text but the listener has a set of guiding questions to ask the reteller so that it looks like an interview. The design of the questions can encourage the use of the target vocabulary from the written text and ensure all the important parts of the text are retold. Both the listener and the re-teller study the text and questions before the retelling and they can rehearse the retelling to perform before others.

When observing the retelling activities, the teacher looks for the use of the wanted vocabulary to see if it is salient enough to encourage its use in the retelling process and to see if it is being used generatively in the retelling.

\section{APPENDIX}

\section{How to calculate the size of the word families?}

To obtain the passive and controlled active vocabulary size, a calculation was done as follows:-

The first 1000 level and the second are assumed to have the same score, the $4^{\text {th }} 1000$ level score is taken as an average of the $3^{\text {rd }}$ and $5^{\text {th }}$ levels. The sum of the scores at all the levels is multiplied by 5000 (as the test without the $10^{\text {th }}$ level represents a size of 5000 word families) and divided by 108 (18 items per level for 6 levels- 1,2,3,4,5, UWL). Even though learners were tested on 72 items ( 4 levels + UWL), two missing levels, 1 and 4 are 'filled in'. The UWL is not a separate frequency level, but consists mainly of words at $4^{\text {th }}$ and $5^{\text {th }}$ level. Therefore it is added to the 5000 sample.(Laufer, 1998)

i) Calculating the word family size of the passive vocabulary knowledge
a) Semester 1
b) Semester 2
c) Semester 3
$\frac{33.01 \times 5000}{108}$
$\underline{35.72 \times 5000}$
$\frac{42.51 \times 5000}{108}$
$=1528.2$
$=1528$
$=1653.7$
$=1653$
$=1968.1$
$=1968$

ii) Calculating the word family size of the controlled active vocabulary knowledge
a) Semester 1
$36.53 \times 5000$
108
b) Semester 2
$45.71 \times 5000$
c) Semester 3
$=1691.2$
108
$\frac{46.53 \times 5000}{108}$
$=1691$
$=2116.2$
$=2154.2$
$=2154$

\section{REFERENCES}

[1] Arevant, S. \& I.S.P. Nation. (1991). Fluency improvement in a second language. RELC Journal, 22, 1, 84-94.

[2] Bacha, N.N. (2001). Writing evolution: What can analytic versus holistic scoring tell us? System, 29, 3: 371-383.

[3] Brett, A., Rothlein, L. \& Hurley, M. (1996). Vocabulary acquisition from listening to stories and explanations of target words. The Elementary School Journal, 96, 415-422. 
[4] Cervatiuc, A. (2007). Highly Proficient Adult Non-Native English Speakers' Perceptions of their Second Language Vocabulary Learning Process. Unpublished PhD Dissertation. Calgary: University of Calgary

[5] Dušková, L. (1969). On sources of error in foreign language teaching. International Review of Applied Linguistics, 7, 11-36.

[6] Elley, W.B. (1989). Vocabulary acquisition from listening to stories. Reading Research Quarterly, 24, 174-187

[7] Ellis, R. (1994). The study of second language acquisition. Oxford: Oxford University Press.

[8] Folse, K.S. (2004). Vocabulary myths: Applying second language research to classroom teaching. Ann Arbor: The University of Michigan Press.

[9] Goulden, R., Nation, P., \& Read, J. (1990). How large can a receptive vocabulary be? Applied Linguistics, 11(4), $341-363$.

[10] Hulstijn, J.H. (1992). Retention of inferred and given word meanings: Experiments in incidental vocabulary learning. In P. Arnaud \& H. Béjoint (Eds.), Vocabulary and applied linguistics (pp. 113-125).

[11] Hwang K. \& Nation, P. (1989). Reducing the vocabulary load and encouraging vocabulary learning through reading newspapers. Reading in a Foreign Language, 6(1), 323-335.

[12] Joe, A. (1994). The effect of text-based tasks on incidental vocabulary learning. Unpublished MA thesis, Victioria University of Wellington.

[13] Johnson, D.D., Johnson, B.V.H., \& Schlicting, K. (2004). Logology: Word and language play. In J.F. Baumann \& E.J. Kame'enui (Eds.), Vocabulary instruction: research to practice (pp. 179-200). New York: Guilford.

[14] Laufer, B. (1994). The lexical profile of second language writing: Does it change over time. RELC Journal, 25, 21-33.

[15] Laufer, B. (1995). Beyond 2000: A measure of productive lexicon in a second language. In L. Eubank, L. Selinker and M. Sharwood-Smith (Eds.), The CurrentState of Interlanguage (265-272), Amsterdam: John Benjamins.

[16] Laufer, B. (1997). The lexical plight in second language reading. In James Coady and Thomas Huckin (Eds.), Second language vocabulary acquisition (pp. 20-34). Cambridge: Cambridge University Press.

[17] Laufer, B. \& Nation, P. (1995). Vocabulary size and use: Lexical richness in L2 written production. Applied Linguistics, 16: 307-322.

[18] Laufer, B. \& Paribakht, T.S. (1998). The relationship between passive and active vocabularies: Effects of language learning context. Language Learning, 48(3): 365-391.

[19] Lehr, F., Osborn, J., \& Hiebert, E.H. (2005). A focus on vocabulary. Retrieved May 28, 2009 from http://www.prel.org/products/re_/ES0419.htm

[20] Linnarud, M. (1986). Lexis in compositions: A performance analysis of Swedish learners' written English. (Lund Studies in English 74). Malmo: Liber Forlag (CWK Gleerup).

[21] Longman language activator. (1993). Harlow, England: Longman.

[22] Maurice, K. (1983). The fluency workshop. TESOL Newsletter, 17, 29-32.

[23] Milton, J. \& Meara, P. (1995). How periods abroad affect vocabulary growth in a foreign language. ITL Review of Applied Linguistics, 107/108, 17-34

[24] Nagy, W.E. \& Scott, J.A. (2000). Vocabulary process. In M.L. Kamil, P. Mosenthal, P.D. Pearson \& R. Barr (Eds.), Handbook of reading research (Vol. 3, pp. 269-284). Mahwah, NJ: Erlbaum.

[25] Nation, I.S.P. (1990). Teaching and learning vocabulary. Heinle \& Heinle, Boston, MA.

[26] Nation, I.S.P. (1999). Learning vocabulary in another language. Victoria University of Wellington: English Language Institute Occasional Publication No. 19.

[27] Nation, I.S.P. (2001). Learning vocabulary in another language. Cambridge, England: Cambridge University Press.

[28] Nation, I.S.P. (2006). How large a vocabulary is needed for reading and listening? Canadian Modern Languages Review, 63, 59-82.

[29] Nation, P. \& Waring, R. (1997). Vocabulary size, text coverage and word lists. In Vocabulary: Description, acquisition and pedagogy, ed. N. Schmitt and M. McCarthy, 6-19. Cambridge University Press.

[30] Pawley, A. \& Syder, F.H. (1983). Two puzzles for linguistic theory: Nativelike selection and nativelike fluency, in J.C. Richards and R.W. Schmidt (eds.), Language and Communication (191-225), London: Longman.

[31] Qian, D. (2002). Investigating the relationship between vocabulary knowledge and academic reading performance: An assessment perspective. Language Learning, 52 (3), 513-536.

[32] Qian, D. \& Schedl, M. (2004). Evaluation of an in-depth vocabulary knowledge measure for assessing reading performance. Language Testing, 21 (1), 28-52.

[33] Schmitt, N. (2007). Vocabulary in language teaching. Cambridge: Cambridge University Press.

[34] Scholfield, P. (1997). Vocabulary reference works in foreign language learning. In N. Schmitt \& M. McCarthy (Eds.), Vocabulary: Description, acquisition, and pedagogy (pp. 279-302). Cambridge: Cambridge University Press.

[35] Schonell, F.J., Meddleton, I.G. \& Shaw, B.A. (1956). A study of the oral vocabulary of adults. Brisbane: University of Queensland Press.

[36] Simcock, M. (1993). Developing productive vocabulary using the "Ask and Answer" technique. Guidelines, 15, 1-7.

[37] Trappes-Lomax, H. (1997). Oxford learners' wordfinder dictionary. Oxford: Oxford University Press.

[38] Weigle, S.C. (2002). Assessing writing. Cambridge: Cambridge University Press.

[39] Wunsch, D.R. (1986). Action research in business education. Business Education Forum. XXXX(5): 31-33.

[40] Xue, G. \& Nation, I.S.P. (1984). A university word list. Language Learning and Communication, 3, 215-229.

[41] Zechmeister, E.B., Chronis, A.M., Cull, W.L., D’Anna, C.A. \& Healy, N.A. (1995). Growth of a functionally important lexicon. Journal of Reading Behavior, 27(2), 201-212.

Ahmad Azman Mokhtar is a senior English lecturer at Universiti Teknologi MARA, Perlis, MALAYSIA. He earned his B.Ed.TESL (Hons.) from Universiti Kebangsaan Malaysia, M.Sc. TESL from Universiti Putra Malaysia, and Ph.D TESOL from Universiti Sains Malaysia. 